
\title{
25 Research Soure \\ Limit Analysis, Numerical and Physical Modelling of Pile Stabilized Slopes
}

\section{Ahmadreza Mazaheri}

Ayatolla Borujerdi University

Rasoul Alipour ( $\nabla$ civil.alipour@gmail.com )

Shahrekord University Faculty of Technology and Engineering https://orcid.org/0000-0001-9425-1369

Masoud Paknahad

mpaknahad@mahallat.ac.ir

\section{Research Article}

Keywords: Factor of safety, Earth Slope, Experimental Model, Image Processing System

Posted Date: April 15th, 2021

DOI: https://doi.org/10.21203/rs.3.rs-359633/v1

License: (c) (i) This work is licensed under a Creative Commons Attribution 4.0 International License.

Read Full License 


\section{Abstract}

Vast researches have been performed in the field of earth slope stability analysis including limit equilibrium, strength reduction, and limit analysis methods. All the available methods present slope safety factors in a range with a bit of difference and confirm each other. Validation of analytical results performs with instrumentation in actual slopes existing in the field. Also, another approach that uses for validating results is experimental modeling. The physical modeling requires manufacturing of the intended model in the laboratory concerning the reducing effect of dimensions on the other parameters. This paper investigates slope safety factors against sliding by simulating the slopes in the laboratory and with an image processing system. The test container has dimensions of $1.5 \times 1.5 \times 2 \mathrm{~m}$. The results have illustrated the crest displacement in reinforced slope, with increasing slope angle 13 degrees, is $30 \mathrm{~mm}$ in the experimental test and $13 \mathrm{~mm}$ in numerical modeling. In the unreinforced slopes, when the slope angle increased by 8 degrees, the experiment test failed, and the factor of safety in the numerical modeling is less than one.

\section{1- Introduction}

Slope stability was investigated by different methods. These methods have been categorized into three groups consist of Limit Equilibrium (L.E.), Limit Analysis (L.A.), and Strength Reduction method (S.R.M.). In the limit equilibrium method, the wedge is divided into several pieces, and the equilibrium of forces and moments, are written in each piece, and finally, the whole wedge balance and safety factor against sliding are determined [1-3]. The use of limit analysis methods in actual complex problems is of limitation $[4,5]$. An upper and lower limit are considered in the limit analysis, which in the upper limit, the assumptions of flow principle and application of energy balance in inter-point vertical and inclined surfaces are considered along the sliding surface [4-7]. The shear strength reduction method also has been utilized by many researchers for slope stability analysis [8-11]. Also, wide researches have been conducted in the field of earth slope stability by using a row of piles and various scientists have studied the behavior of exerted forces to the piles and the slope factor of safety by using analytical relations and numerical modeling [12-22].

Also, many studies perform concerning the experimental investigation of earth slopes. Some cases are mention in the following. Vakil et al. [23] have studied the bearing capacity and settlement of a foundation constructed on an earth slope reinforced with stone columns by experimental modeling and numerical analyses. They used soft clay in their laboratory model and compacted the slope layers in thicknesses of $50 \mathrm{~mm}$. Orenes et al. [24] have studied the factors affecting failure initiation. For this purpose, a series of experimental modeling performs on sandy slopes, and they investigated failure conditions in the slopes by using the artificial load method and seepage. Lee et al. [31], Sharafi and Sojoudi [32], Hajiazizi et al. [33], and Mazaheri [33] have been studied the effect of slope stabilization on the concrete pile. 
Image processing systems have been used for several years in the researcher's studies, especially in studying fluid dynamics [25-26]. However, the use of this system is less discusses in Civil and Geotechnical engineering works. White et al. [27] measured soil deformation by conducting the image processing system. Also, they have published a guideline for using this system in soil mechanics [28]. Ould Baba and Peth [29] have examined the suitability of Particle Image Velocimetry (PIV) in investigating creep on slopes by experimental tests. These methods use to validate the modeling results.

As it was mentioned, various researches have been performed in the field of investigating earth slopes by the use of numerical analyses, analytical relations, and experimental modeling; however, it is not used from the image processing system to monitor slopes movement in the performed studies, up until the present time. Furthermore, previous laboratory tests have been done in boxes with small dimensions, so that the use of large boxes and image processing to examine the slope displacement is remarkable. In the present study, a slope with primary characteristics designed, and the rest of the investigations are proceeding based on the proposed slopes.

\section{2- Statement Of The Problem}

This paper is an attempt to make a comparison between numerical analyses, and experimental studies by the employment of laboratory equipment and the image processing system. For this purpose, an earth slope is first designed based on the existing soil properties that are summarized in Table 1. For determining sand properties in Table 1 Standard test method of ASTM D3080, ASTM D1556, and ASTM C127 have been used. This slope has been depicted in Fig. 1.

The given slope having the dimensions presented in Fig. 1 and the properties summarized in Table 1 is a model in Plaxis and Geo-Slope software. Initial safety factors of 1.35 and 1.37 have been obtained from Plaxis and Slope/w software, respectively. Therefore, it is obvious that the introduced slope is stable in its primary state.

\section{3- Experimental Studies 3- Experimental studies}

To do experimental studies of the earth slope, a box container with dimensions of $1.5 \times 1.5 \times 2 \mathrm{~m}$ has been manufactured. It was used from a $10 \mathrm{~mm}$ thick glass in the two large sides of the box to monitor the earth's slope behavior. Regarding the box dimensions, earth slopes with heights up to $12 \mathrm{~m}$ can be model with a scale of $1 / 10$. The preparation process of the model is described in the following, step by step.

At first, according to the soil properties that were presented in Table 1, the earth slope sample was prepared by placing $100 \mathrm{~mm}$ layers with dry pluviation technique, and by repeating this procedure and changing the height of pluviating soil material, the required compaction was provided. To reduce friction between the soil material; and the glass wall, a transparent sheet layer was attached to the glass, and it was also used as a lubricant to reduce friction between the transparent sheet and the glass. Moreover, it 
should be noted that the transparent sheet has been applied stratified because unified applying of the sheet would prevent proper behavior of the soil. In Table 2, the number of tests depicted.

During the preparation of the earth slope, the soil is placed in $100 \mathrm{~mm}$ layers with dry pluviation technique, and to control the slope movement, it was used from wooden cylinders with $20 \mathrm{~mm}$ of diameter and $50 \mathrm{~mm}$ of height in the container, which their base have been grinded and painted with red color. The height of $50 \mathrm{~mm}$ is used with the aim that the woods are involved with the soil, completely and their behavior is quite consistent with the soil behavior. These wooden pieces are located in pre-specified places marked on the side glass with $100 \mathrm{~mm}$ distance from each other. The testing box container and the used wooden cylinders have been illustrated in Fig. 2 .

Regarding the large size of the box, the use of weight to create overstress to increase force and reduce safety factor is difficult. From the other side, with regards to being of glass the box sides, the use of weight might be risky work. For this purpose, to reduce the slope safety factor and destabilize, it was decided to increase the slope angle. In this regard, a base along with a crane was improvised on a side of the slope and the slope angle became changeable during the test with the help of a cable attached to the slope side and the crane.

The performed experiments can be divide into two major groups of reinforced and unreinforced earth slopes. In the reinforced slopes, there are using from piles with different distances to stabilize the slopes. To determine the pile's diameter and stiffness in manufacturing laboratory models, it is required to perform dimension analysis and the moment of inertia and stiffness are required to be selected so that they have an adequate consistency with the actual slope in nature. In this study, the ratio equal to $1 / 10$ was adopted in the preparation of the laboratory model.

According to the available references [30], in the determination of pile stiffness in the laboratory model, the material modulus of elasticity changed by the ratio of $\frac{1}{n^{\alpha}}$, where $\alpha$ is introduced equal to 0.5 and 1 for sand and clay soils, respectively. To determine the pile moment of inertia in the laboratory model, it is required that

the ratio of $\frac{1}{n^{4+\alpha}}$ be considered. For modeling an actual concrete pile with a diameter of $800 \mathrm{~mm}$, a section must be selected so that the moment of inertia resulted from applying the intended coefficient is equivalent to the actual model. In the laboratory model, a PVC tube with a diameter of $100 \mathrm{~mm}$ and wall thickness of $2 \mathrm{~mm}$ placed sandy soil is equivalent to a pile with a diameter of $800 \mathrm{~mm}$ in the actual model.

\section{3-1- Unreinforced Slope}

To investigate the behavior of earth slopes, the earth slope prepares by the above-described procedure, and the wooden cylinders are employed in specific points with a distance of $100 \mathrm{~mm}$ from each other. There is a typical slope shown in Fig. 3. To determine the failure wedge in the slope, and the sliding path, a side of the slope was raised with the help of the crane. During increasing of the slope angle, the whole 
movement is recorded by using a camera that is installed in front of the slope. An increase in the slope angle will be continued until the slope collapses.

\section{3-2- Slope Reinforced by Pile}

As it was described, it could be used from a $100 \mathrm{~mm}$ diameter tube for reinforcing the slope in the prepared laboratory model. In the modeling of slopes reinforced by piles, the distance between piles and the fixity of pile end are the most important parameters. To fix the pile end, a foam layer is embedded at $200 \mathrm{~mm}$ at bottom of the box. This foam layer has two proper functions; one is providing fixity of the pile end and the other is preventing stress concentration and avoiding pressure to be exerted on the glass sides during increasing of the slope angle.

In the pile-reinforced slopes, pile distances ranging from 1 to 5 times the pile diameter have been examined, and the whole movement is video recorded during an increase in the slope angle. During all tests, in addition to monitoring the general path of movement, displacement in 5 specific points including the slope crest, slope heel, slope middle on the ground surface and the slope middle-upper and lower than the sliding surface has been assessed and taken into comparison.

\section{4- Numerical Modeling}

Two software including Plaxis and Slope/w have been used for numerical analysis of the reinforced and unreinforced slopes prepared in the laboratory. The slope characteristics in the numerical model were considered equal to the laboratory model parameters presented in Table 1. A typical model created in the software is illustrated in Fig. 4.

\section{5- Limit Analysis}

Limit Analysis (LA) theorem can be used to examine the safety of earth slope in Geotechnical Engineering. To solve slope stability problems, the use of limit analysis has almost exclusively concentrated on the kinematic theorem [35-37], because under certain assumptions, this is generally simpler to use than the static approach. Application of the kinematic theorem requires equating the rate of work done by tractions and body forces to the internal energy dissipation rate, for any assumed strain rate field which is governed by the normality rule and is compatible with the velocities at the boundary of the failing soil mass (kinematically admissible failure mechanism). This can be expressed by the following work equation.

$\int_{S} T_{i} v_{i} d S+\int_{V} X_{i} v_{j} d V=\int_{S} \sigma_{i j} \varepsilon_{i j} d V$

3

$$
i, j=1,2 \text {, }
$$

where $^{X_{i}}=$ body forces; ${ }^{T_{i}}=$ traction; $^{v_{i}}=$ kinematically admissible velocity field; ${ }^{\varepsilon_{i j}}=$ strain rate field compatible with ${ }^{v_{i}} ; \sigma_{\ddot{i}}=$ stress field relating to $X_{i}$ and $T_{i}$ [38].

The rotational log-spiral collapse mechanism, which was earlier examined by Chen [35] and many other researchers, is adopted herein. The geometry of the failure surface (Fig. 1) is described by the log-spiral equation. 
$r=r_{0} e^{\left(\theta-\theta_{0}\right) \frac{t g_{\varphi}}{F S}}$

where $\mathrm{r}_{0}=$ radius of the log-spiral with respect to angle $\theta$.

The most effective position of the piles within the slope is where the stabilizing force needed to increase the safety factor to the desired value takes the minimum value. The effects of pile location on the required Fp, the force exerted on unit width of sliding mass by the piles, show that if the retaining force that a row of piles can provide is large enough, the piles should be installed near the toe of the slope where the stabilizing force can produce maximum stabilization results. It also indicates that the most economic location for piles in slope stabilization is near the toe of the slope [16].

In this research, a comparison between laboratory model, limit analysis, and numerical analysis with an increase in the slope angle has been depicted in Table 2.

\section{6- Results And Examinations}

As it was described in the previous sections, an earth slope was manufactured and analyzed both numerically and experimentally. In this section, the results obtained from investigations are presented in several sub-sections.

\section{6-1- studying slope displacement by the help of image processing system}

In the experimental studies, all steps of the work were being photographed. After performing the tests, the recorded images have been processed by using MATLAB software, and the overall displacements of the specified points have been evaluated for both reinforced and unreinforced slopes. In Fig. 6, an example of the images processed in the software is shown for different testing times. There are ten images in the figure, which were captured with increasing the earth slope angle. As is obvious in Fig. 6 (image 10), the sliding wedge of the slope could be determined.

Images were also taken during increments of the slope angle for the pile-reinforced earth slope. A comparative illustration presents in Fig. 7 between displacements of the points corresponding to both reinforced and unreinforced earth slopes.

As is clear from the comparison of Figs. 7(a) and 7(b), reinforcement of slopes has a significant influence on reducing slope displacements. Figure 7(a) represents displacements of points in the unreinforced slopes with an increase of 8 degrees in the slope angle. Figure 7(b) demonstrates displacements of points in the pile-reinforced slope with pile distances of 3 times its diameter and an increase of 13 degrees in the slope angle. As is clear, by increasing the reinforced slope angle up to 13 degrees, there is not only no falling occurred, but also its points' displacements are much less than the corresponding displacement of the unreinforced slope with an 8-degree increase of the angle. In the unreinforced slope, a displacement of about $90 \mathrm{~mm}$ occurs in the points inside the wedge with a slope rotation equal to 8 
degrees; however, in the slope reinforced by 2 piles, a maximum displacement of $30 \mathrm{~mm}$ takes place with a slope rotation equal to 13 degrees.

\section{6-2- Comparison of slope safety factors of laboratory and numerical models}

In the laboratory model, a slope with before-described characteristics is prepared and its safety factor has been calculated in the software. The slope angle is increased gradually and along with it, displacements are measured in special points at the middle of the slope. Also, in the numerical analysis, slope angle variation imitates the experiment and finally, the obtained results have been taken into comparison.

As it can be observed in Fig. 8(b), displacement at 5 different points in the numerical model (including the slope crest, slope heel, slope middle on the ground surface, the slope middle inside the wedge and near the sliding surface, and the slope middle out of the failure wedge) have been measured. These displacements are shown in Fig. 9 when the slope angle is increased by 10 degrees.

As it can be seen in Fig. 9, the slope safety factor reaches a value less than 1 when the slope angle is increased by 10 degrees. This causes the slope to be failed and increases displacement in different points of the slopes. The maximum displacement is related to point $A$ on the top of the slope crest is equal to $80 \mathrm{~mm}$. The difference between displacements of points $D$ and $E$ implies that point $D$ is located inside the wedge, while point $E$ is out of it.

\section{6-3-Comparison of results of laboratory model and numerical analysis in the unreinforced slope}

In the following, to investigate and compare results from laboratory model and numerical analysis, the slope displacement and its safety factor have been determined by changing the slope angle. The results present in Table 3.

\section{6-4- Comparison of results of laboratory model and numerical analysis in the reinforced slope}

As it was described, there have been used from Poly Vinyl Chloride, P.V.C., tubes with a diameter of 100 $\mathrm{mm}$ and wall thickness of $2 \mathrm{~mm}$ in the laboratory modeling to reinforce the slopes. According to the previous studies [13], the best place of the slope for pile installation is at the middle area and the most appropriate pile performance is when it is fixed-end. Therefore, it was used from a $200 \mathrm{~mm}$ thick foam layer, which the pile end goes down into it, to simulate a fixed-end type pile. Thus, in the laboratory models reinforced by piles, all the piles are installed at the middle of the slope and are plunged into the foam layer. The models have been tested with pile distances of $1 D, 2 D, 3 D$, and $4 D$, where $D$ is the pile diameter. The obtained results are compared with the results from numerical analysis of the slopes. Figure 11 shows a typical laboratory model. 
As is specified in Fig. 11, slopes with different conditions of reinforcement have been prepared and evaluated. Similar to the previous case, the angle of the reinforced slope was also increased to destabilize it; meanwhile, all displacements of the slope have been photographed. The same procedure is also fulfilled in the software and their results are compared with each other. In the slopes reinforced by pile, an increase of the slope angle has been continued up to 13 degrees. The results are summarized in Table 4.

It could be found from Table 4 that the minimum displacement of different points of the slope (including the slope crest) occurs when the piles are installed with a distance equal to their diameter.

\section{6-5- Evaluating Slope Stabilization in a Complex Landslides by Concrete Pile; Case Study in the west of Iran}

The Iran Gas Trunkline (IGAT) is a series of large diameter pipelines constructed from gas refineries in the south of Iran (Khuzestan and Bushehr provinces) $n$ order to transfer natural gas to consumption centers across the country.

IGAT6, 56 inches $(1,420 \mathrm{~mm})$ in diameter, transfers natural gas produced in South Pars phases 6 to 10 from Asalouyeh to Khūzestān Province to be consumed there, in the west of the country, and Iraq.

Figure 12 indicates a series of instabilities according to the installing of the underground pipeline. In this figure, there are three sliding slopes. As depicted in Fig. 12, Slope 1 is possible to stabilize by concrete pile.

\section{7- Conclusions}

As it was shown in this paper, the use of an image processing system could be of help in studying the behaviors of earth slopes. The major outcomes are presented in the following:

When the slope angle increasing 8 degrees, the crest displacement in the unreinforced slope is 90 and 76 $\mathrm{mm}$ in experiment test and numerical modeling, respectively. When the slope angle increased 10 degrees in the unreinforced slope, the model was failed in the experimental test, and the factor of safety is 0.98 in numerical modeling.

In the reinforced slope, when the pile distance is five times of pile diameter, increasing the slope angle 13 degrees the crest displacement is equal to 30 and $13 \mathrm{~mm}$ in experiment test and numerical modeling respectively.

Displacements that occurred in different points of the laboratory model have a suitable consistency with numerical modeling; however, in some cases, they got a little greater value. It could correspond to the shaking of the physical model during an increase in the slope angle. 
Until the slope safety factor is greater than 1 (in the safe region), displacement in different points of the slope were negligible and ranged below $10 \mathrm{~mm}$.

\section{References}

1. Bishop AW (1955) The use of slip circles in stability analysis of slopes. Geotechnique, Vol. 5 No. 1 , pp. 7-17

2. Fellunius W (1936) Calculations of the Stability of Earth Dams. Proceedings of the Second Congress of Large Dams. Vol. 4, pp. 445-63, Washington D. C

3. Janbu N (1968) Slope Stability Computations. (Geoteknikk, NTH). Soil Mechanics and Foundation Engineering, Technical University of Norway

4. Spencer E (1967) A method of Analysis of the Stability of Embankments. Assuming Parallel Interslice Forces Geotechnique 17:11-26

5. Cheng YM, Lansivaara T, Wei WB (2007) Two-dimensional slope stability analysis by limit equilibrium and strength reduction methods. Comput Geotech 34:137-150

6. Chen WF (1975) Limit analysis and soil plasticity. Elsevier, USA

7. Sloan SW (1989) Upper bound Limit Analysis using finite elements and linear programing. Int J Numer Anal Meth Geomech 13:263-282

8. Sloan SW (1988) Lower bound Limit Analysis using finite elements and linear programing. International Journal for Numerical and Analytical Methods in Geomechanics, Vol 12,61-77. Song E. Finite element analysis of safety factor for soil structures. Chi J Geotech Eng 1997; 19(2):1-7. in Chinese

9. Ugai K, Leshchinsky D (1995) Three-dimensional limit equilibrium and finite element analysis: a comparison of results. Soils Found 35(4):1-7

10. Zheng YR, Zhao SY, Kong WX, Deng CJ (2005) Geotechnical engineering limit analysis using finite element method. Rock Soil Mech 26(1):163-168

11. Zienkiewicz OC, Humpheson C, Lewis RW (1975) Associated and nonassociated visco-plasticity and plasticity in soil mechanics. Geotechnique 25(4):671-689

12. Hajiazizi M, Mazaheri AR "The Use of the line segments slip surface for location optimization of pile in stabilization of earth slopes", International Journal of Civil Engineering, Volume 13,2015

13. Won J, You K, Jeong S, Kim S (2005) Coupled effects in stability analysis of pile-slope systems. Comput Geotech 32(4):304-315

14. Kourkoulis R, Gelagoti F, Anastasopoulos L, Gazetas G. "Hybrid Method for Analysis and Design of Slope Stabilizing Piles", Journal of Geotechnical and Geoenvironmental Engineering, ASCE, 2012

15. Basu D, Salgado R "Elastic Analysis of Laterally Loaded Rectangular Piles" Geo-Frontiers 2011, ASCE 2011

16. Li X, Pei X, Gutierrez M (2012) "Optimal location of piles in slope stabilization by limit analysis". Acta Geotech 7:253-259 
17. Wei WB, Cheng YM (2009) Strength reduction analysis for slope reinforced with one row of piles". Comput Geotech 36:1176-1185

18. Ashour M, Ardalan H (2012). "Analysis of pile stabilized slopes based on soil-pile in interaction," Computers and Geotechnics

19. Hajiazizi M, Heydari F (2017) Determination of critical slip surface in earth slopes using Alternating Variable Local Gradient. (in Persian), Ferdowsi Civil Engineering, In Press

20. Hajiazizi M, Baveli M, Fakhimi A (2017) Numerical and Experimental Study of the Optimal Location of Concrete Piles in a Saturated Sandy Slope. International Journal of Civil Engineering

21. Hajiazizi M, Mazaheri AR (2016) A New Method for Estimating of displacement and Lateral Force Acting on Stabilizing Piles in Earth Slope. The Modares Journal of Civil Engineering (in Persian) 16(1):189-198

22. Joorabchi $A E$, Liang $R$, $L$. "Yield acceleration and permanent displacement of a slope reinforced with a row of drilled shafts", Soil Dynamics and Earthquake Engineering, 2014, 68-77

23. Vekli M, Aytekin. S, I' kizler., B, Mit. U, Alik. C, (2012) "Experimental and numerical investigation of slope stabilization by stone columns" Nat Hazards 64:797-820

24. Orense. R, Shimoma. M, Towhata SK. I. (2004) “Instrumented model slope failure due to water seepage". Journal of natural Disaster science, Volume 26, Number 1, pp 15-26

25. Adrian RJ (1991) Particle-imaging techniques for experimental fluid mechanics. Ann Rev Fluid Mech 23(1):261-304. http://dx.doi.org/10.1146/annurev.fl.23. 010191.001401

26. Bradley AA, Kruger A, Meselhe EA, Muste M. Flow measurement in streams using video imagery. Water Resour Res 2002; 38(12):51-51. http://dx.doi.org/ 10.1029/2002WR001317

27. White DJ, Take WA, Bolton MD (2001 a) Measuring soil deformation in geotechnical models using digital images and PIV analysis. Proceedings of the 10th International Conference on Computer Methods and Advances in Geomechanics. Tucson, Arizona. pp 997-1002 pub. Balkema, Rotterdam

28. White DJ, Take WA Particle Image Velocimetry (PIV) software for use in geotechnical testing. Cambridge University Engineering Department Technical Report CUED/D-SOILS/TR322

29. Ould Baba H, Peth S (2012) large scale soil box test to investigate soil deformation and creep movement on slopes by Particle Image Velocimetry (PIV). Soil Tillage Research 125:38-43

30. Wood DM "Geotechnical modelling" 2004

31. Lee CY, Hull TS, Poulos HG (1995) Simplified pile-slope stability analysis. Comput Geotech 17(1):116

32. Sharafi $\mathrm{H}$, Sojoudi $Y$ (2016) Experimental and numerical study of pile-stabilized slopes under surface load conditions. International Journal of Civil Engineering 14(4):221-232

33. Hajiazizi M, Nasiri M, Mazaheri AR (2018) The effect of fixed-tip piles on stabilization of earth slopes. Scientia Iranica 25(5):2550-2560

34. Mazaheri AR (2015) Use of line segments slip surface for optimized design of piles in stabilization of the earth slopes. International Journal of Civil Engineering 13(1):14-27 
35. Chen WF (1975) Limit analysis and soil plasticity. Elsevier Science, Amsterdam (The Netherlands)

36. Michalowski RL (1989) Three dimensional analyses of locally loaded slopes. Geotechnique 39(1):27\&\#8211

37. Michalowski RL (1995) Slope stability analysis: a kinematical approach. Geotechnique 45(2):283293

38. Ausilio E, Conte E, Dente G (2001) Stability analysis of slopes reinforced with piles. Comput Geotech 28(8):591-611

\section{Tables}

\section{Table 1}

Initial properties of the tested sand

\begin{tabular}{cccccc}
\hline Properties & $\begin{array}{c}\text { Relative } \\
\text { density }\left(\mathrm{D}_{\mathrm{r}}\right)\end{array}$ & $\begin{array}{c}\text { Cohesion } \\
(\mathrm{kPa})\end{array}$ & $\begin{array}{c}\text { Friction angle } \\
\text { (degree) }\end{array}$ & $\begin{array}{c}\text { Modulus of } \\
\text { Elasticity }(\mathrm{kPa})\end{array}$ & $\begin{array}{c}\text { Specific } \\
\text { gravity } \\
\left(\mathrm{kN} / \mathrm{m}^{3}\right)\end{array}$ \\
\hline Value & $75 \%$ & 1.5 & 24 & 12000 & 18
\end{tabular}

Table 2

Test plan for physical modelling

\begin{tabular}{llc}
\cline { 2 - 3 } 1 & Laboratory models description & Number of performed tests \\
\cline { 2 - 3 } 2 & Rnreinforced Slope & 2 \\
3 & Reinforced slope with pile distance 1D & 2 \\
4 & Reinforced slope with pile distance 2D & 2 \\
5 & Reinforced slope with pile distance 3D & 2 \\
\hline *D & = Pile Diameter, Pile distance is edge to edge distance
\end{tabular}

Table 3

Comparison between laboratory model, limit analysis and numerical analysis with increase in the slope angle

\begin{tabular}{cccc}
\hline $\begin{array}{c}\text { Status of } \\
\text { laboratory model }\end{array}$ & $\begin{array}{c}\text { Safety factor from } \\
\text { numerical analysis }\end{array}$ & $\begin{array}{c}\text { Safety factor from } \\
\text { Limit Analysis }\end{array}$ & $\begin{array}{c}\text { Increasing of angle } \\
\text { (degree) }\end{array}$ \\
\hline Stable & 1.29 & 1.32 & 2 \\
Stable & 1.21 & 1.25 & 4 \\
\hline Low displacement & 1.10 & 1.13 & 6 \\
Failure & 1.02 & 1.05 & 8 \\
Failure & 0.96 & 0.99 & 10 \\
\hline
\end{tabular}


Table 4

Comparison between the results of laboratory model and numerical analysis of the reinforced slopes with 13degrees increase in the slope angle

\begin{tabular}{cccc}
\hline Pile distance & \multicolumn{2}{c}{ Numerical analysis } & Laboratory model \\
\cline { 2 - 4 } & Safety factor & Crest displacement, $\mathbf{~ m m}$ & Crest displacement, $\mathbf{m m}$ \\
\hline 1D & 1.42 & 2 & 15 \\
2D & 1.36 & 4 & 20 \\
3D & 1.25 & 5 & 25 \\
4D & 1.12 & 9 & 30 \\
5D & 1.04 & 13 & 30 \\
\hline
\end{tabular}

\section{Figures}

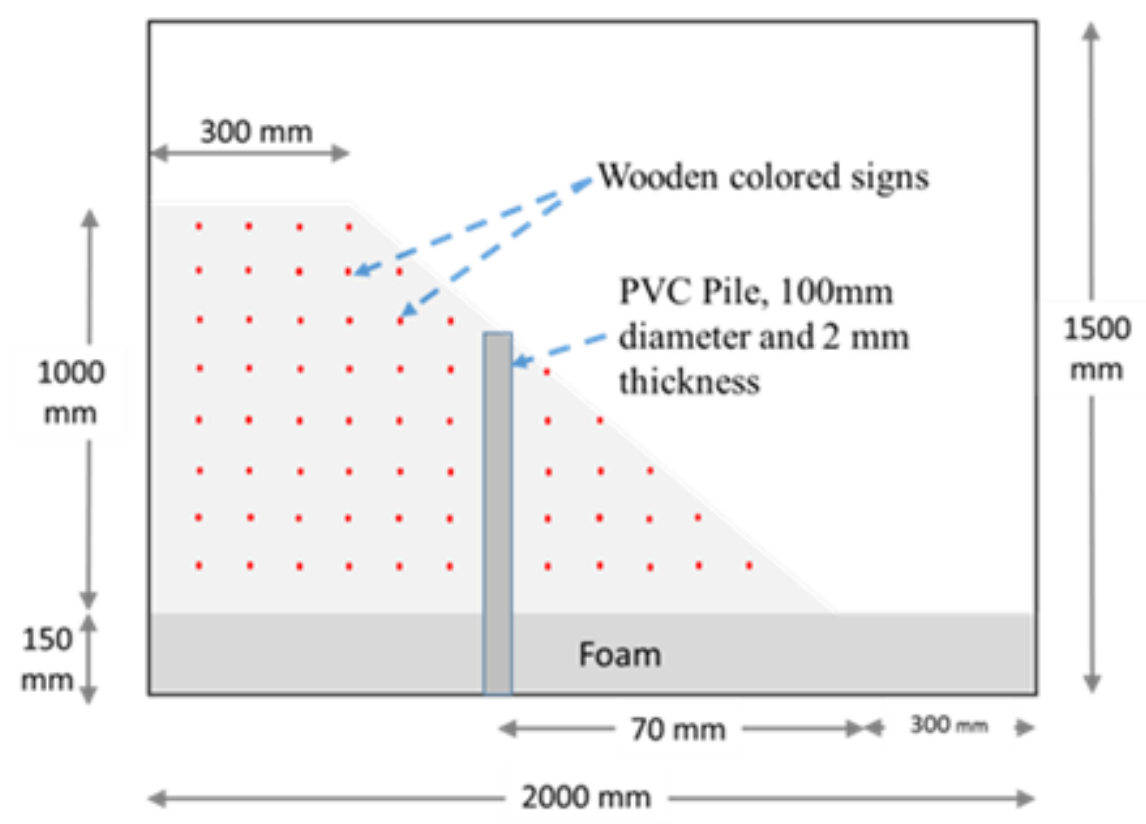

\section{Figure 1}

Schematic illustration of the given earth slope studied in this paper 


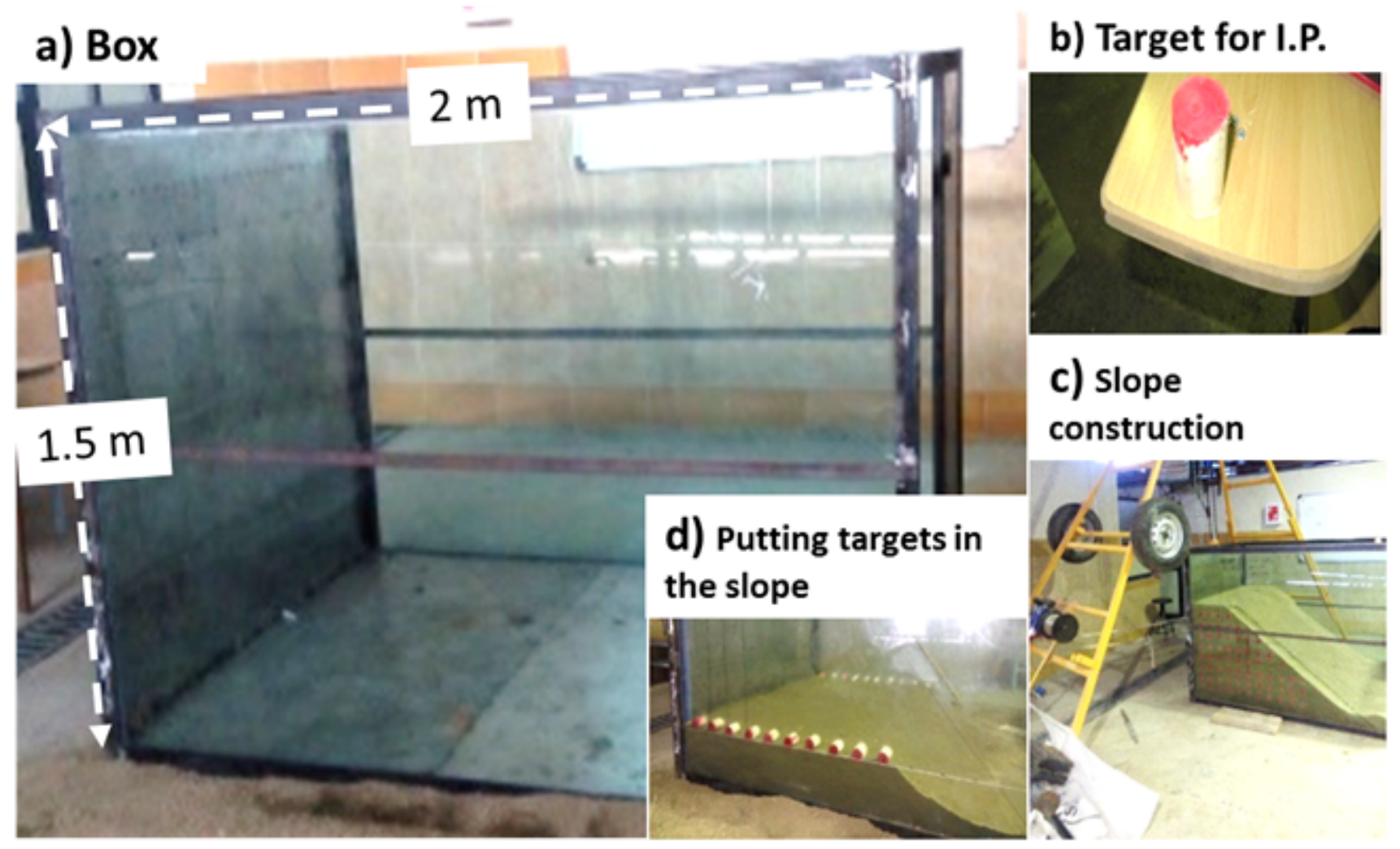

Figure 2

The testing box and pieces used for controlling movement path

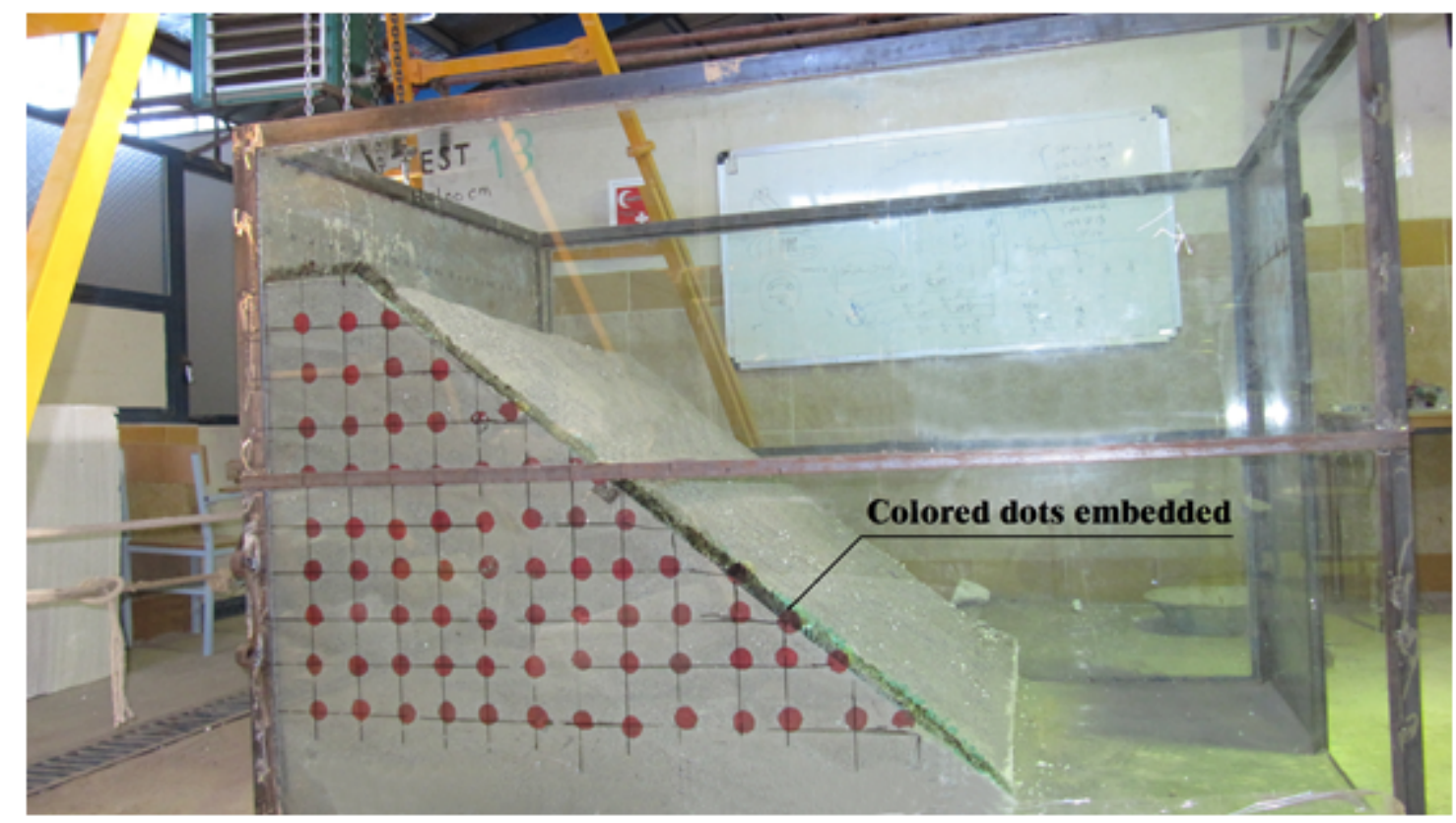

Figure 3

Unreinforced slope prepared in the laboratory and the improvised colored points with specific distances 


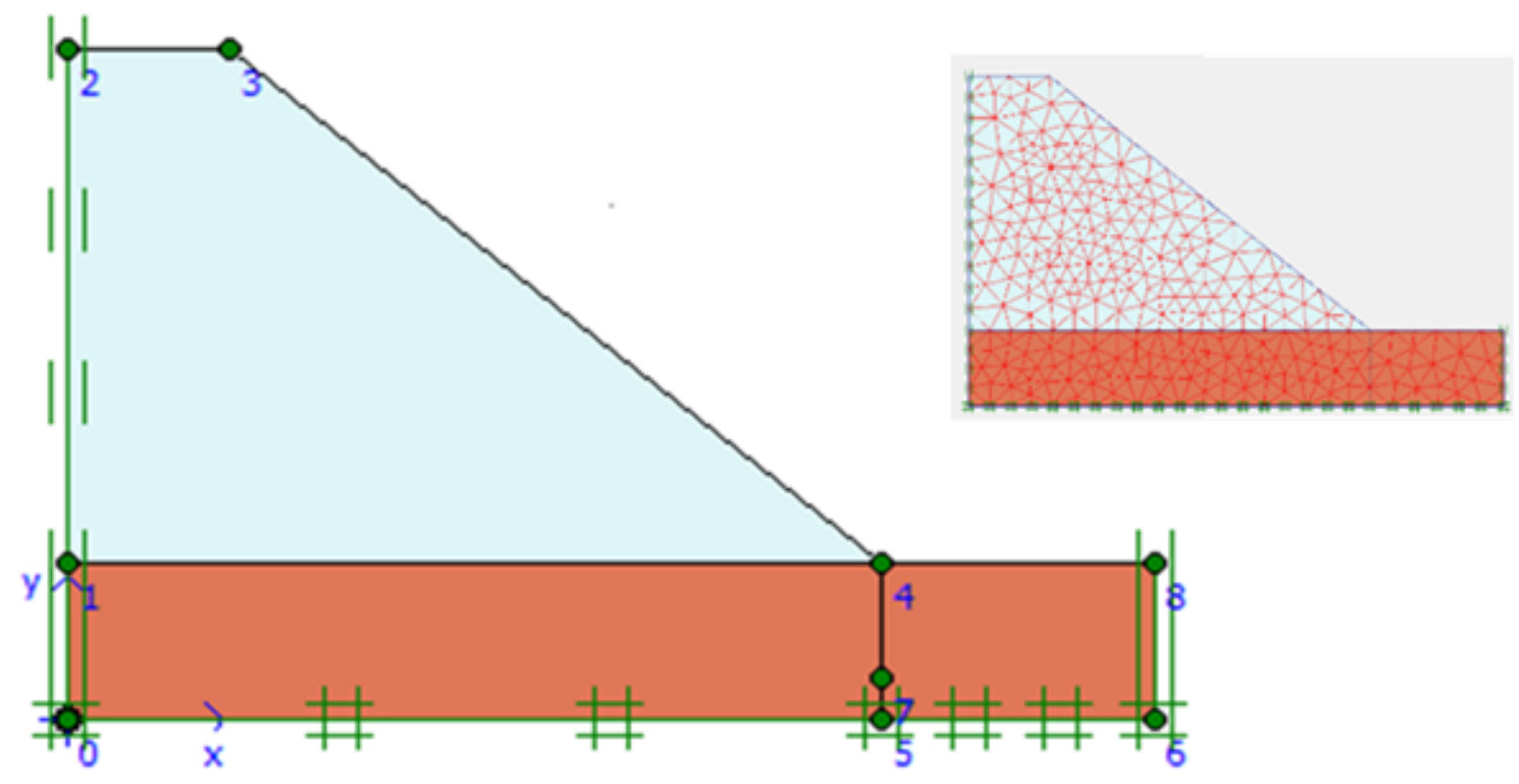

Figure 4

Typical model created in the software

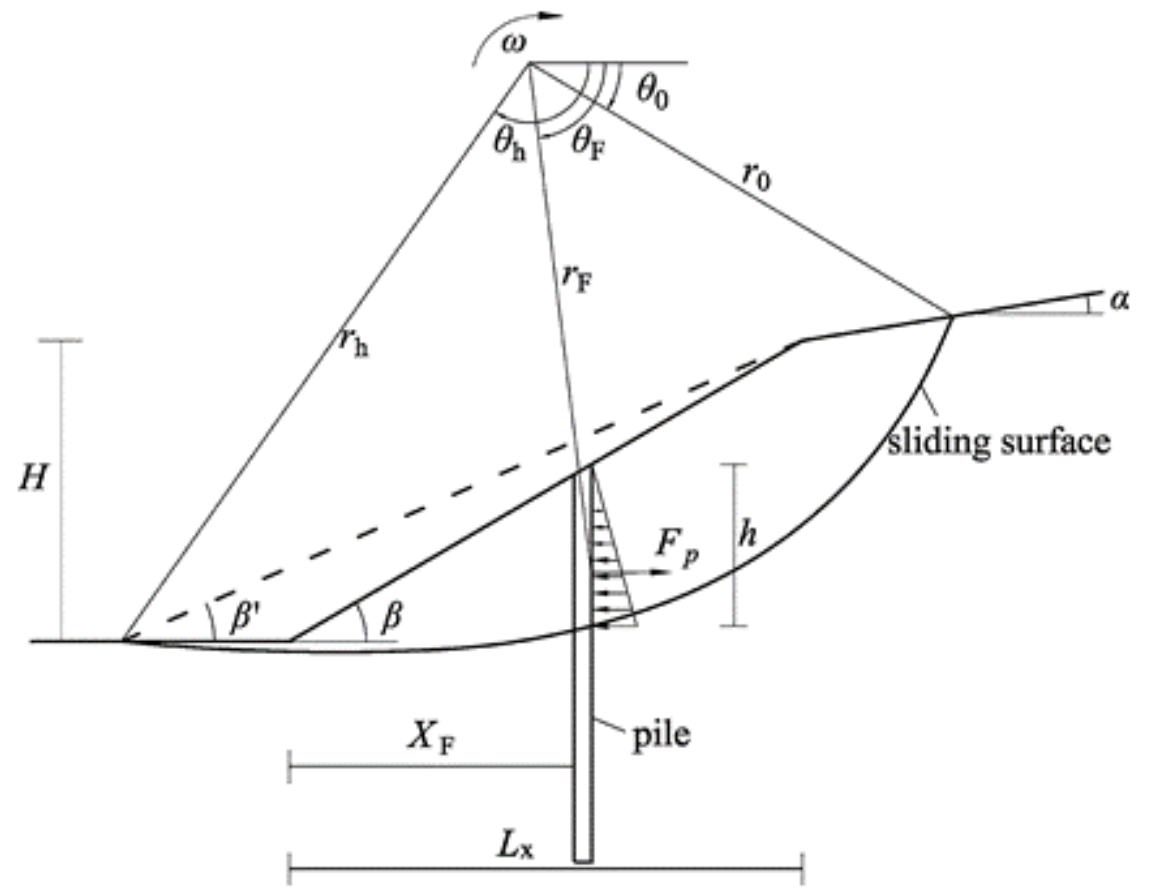

Figure 5

Rigid rotation collapse mechanism for a slope reinforced with a row of piles [16] 


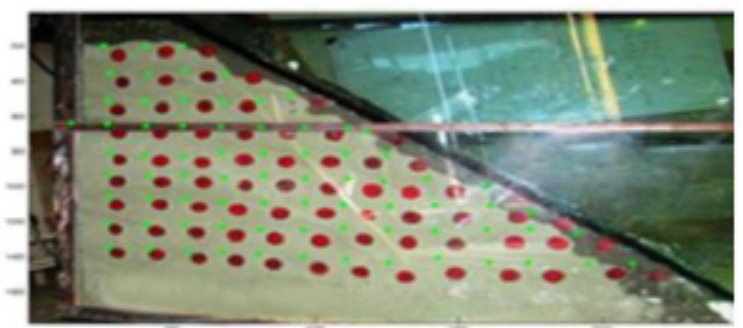

Picture 1

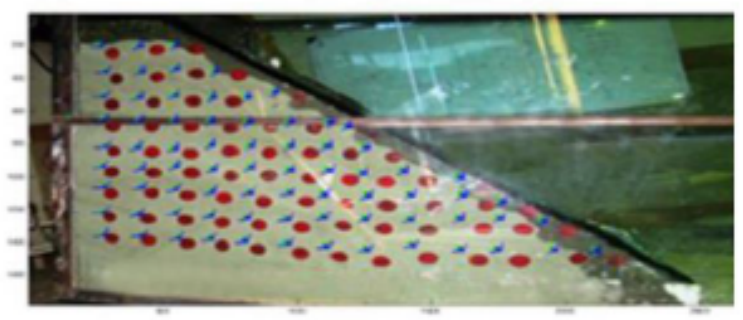

Picture 3

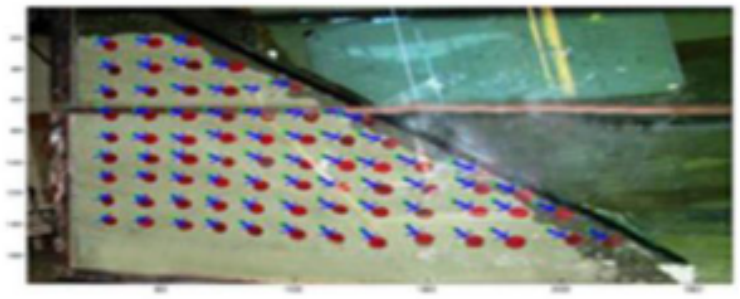

Pictuve 5

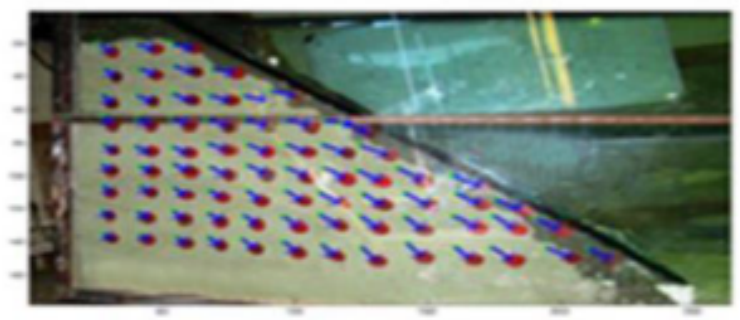

Pictuve 7

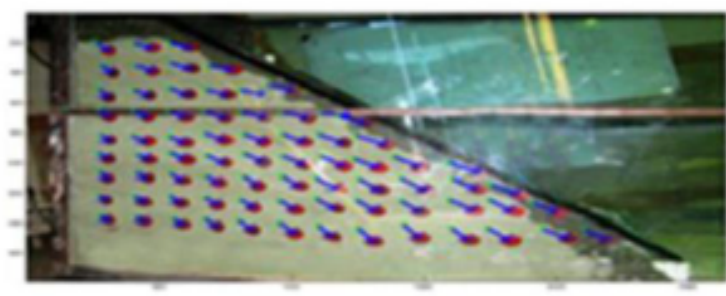

Piccuure 9

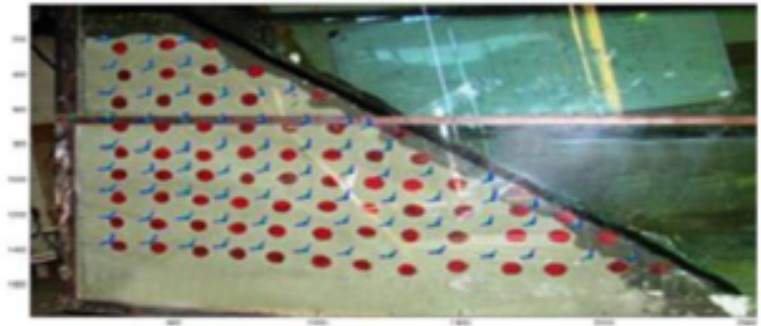

Picture 2

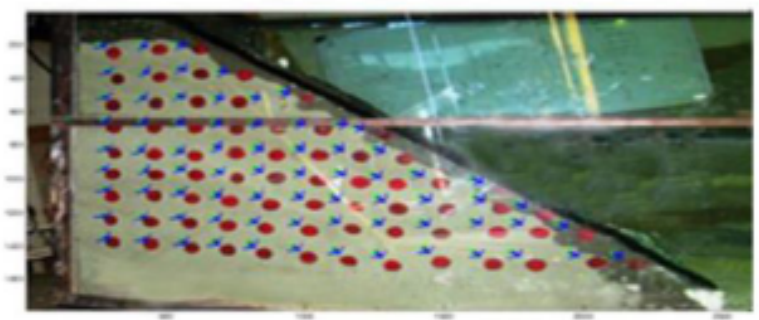

Picfure 4

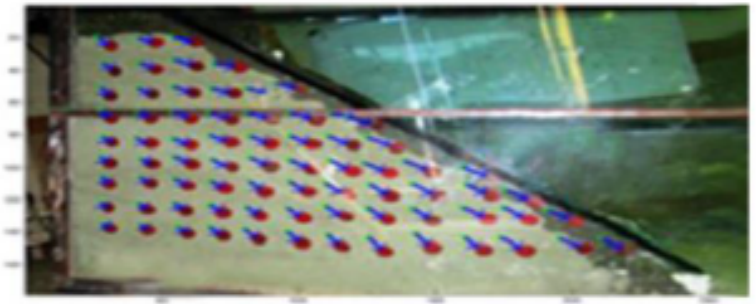

Picnure 6

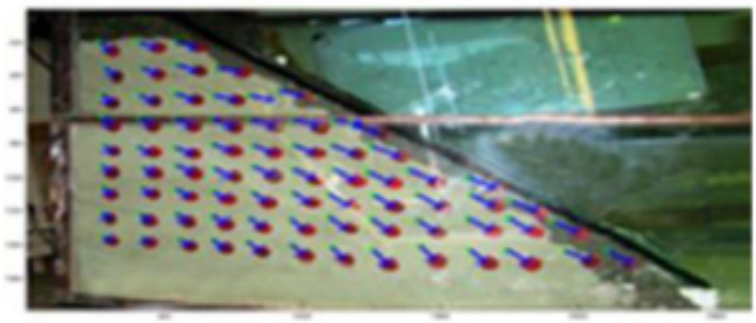

Picnure 8

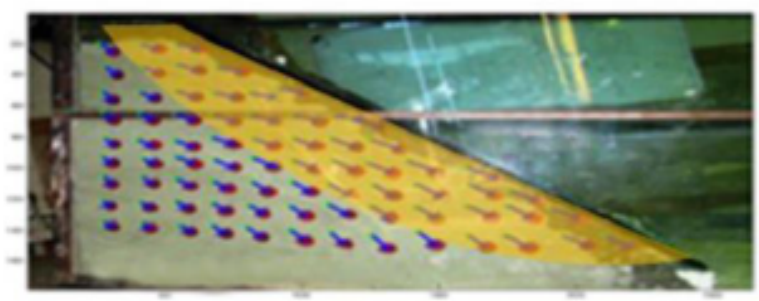

Picnue 10

Figure 6

Controlling slope displacement using image processing system by the help of MATLAB software 


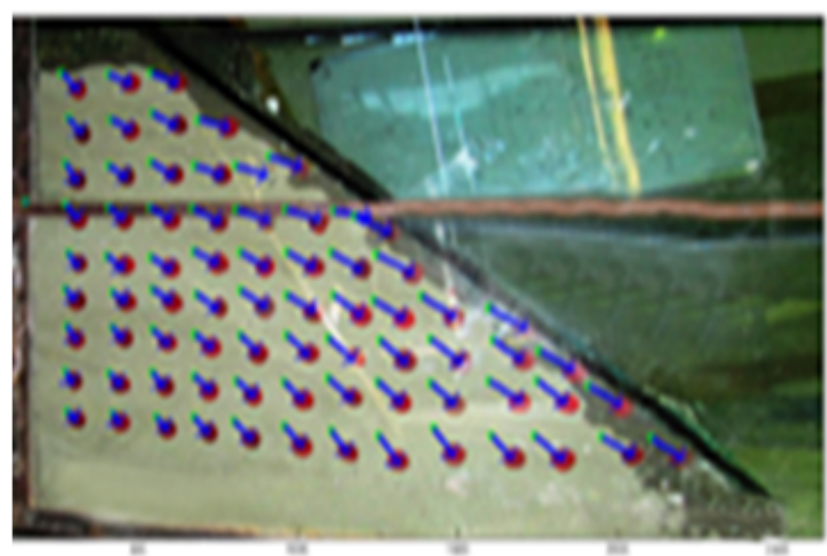

(a)

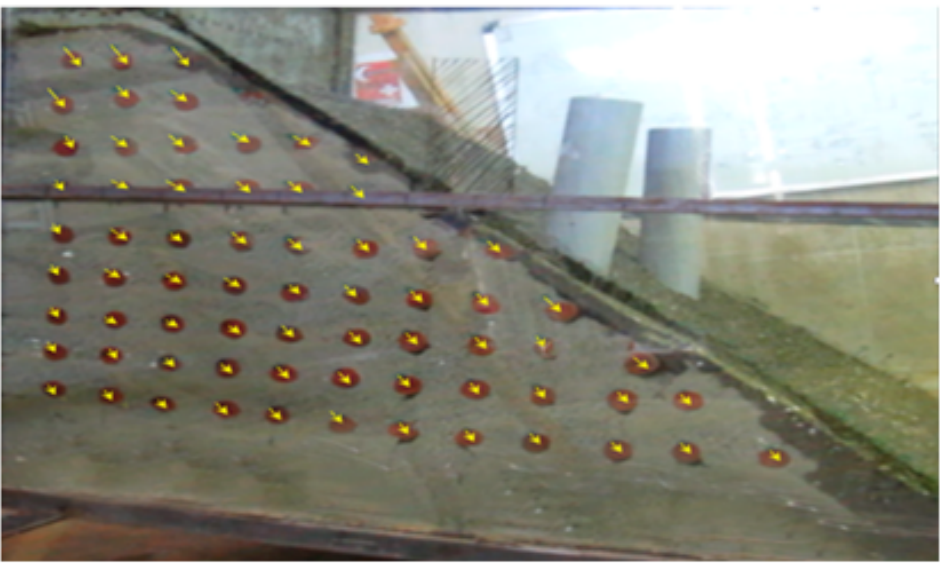

(b)

Figure 7

Comparison between displacements of the points in two identical slope angles, (a) unreinforced slope and (b) slope reinforced by two piles
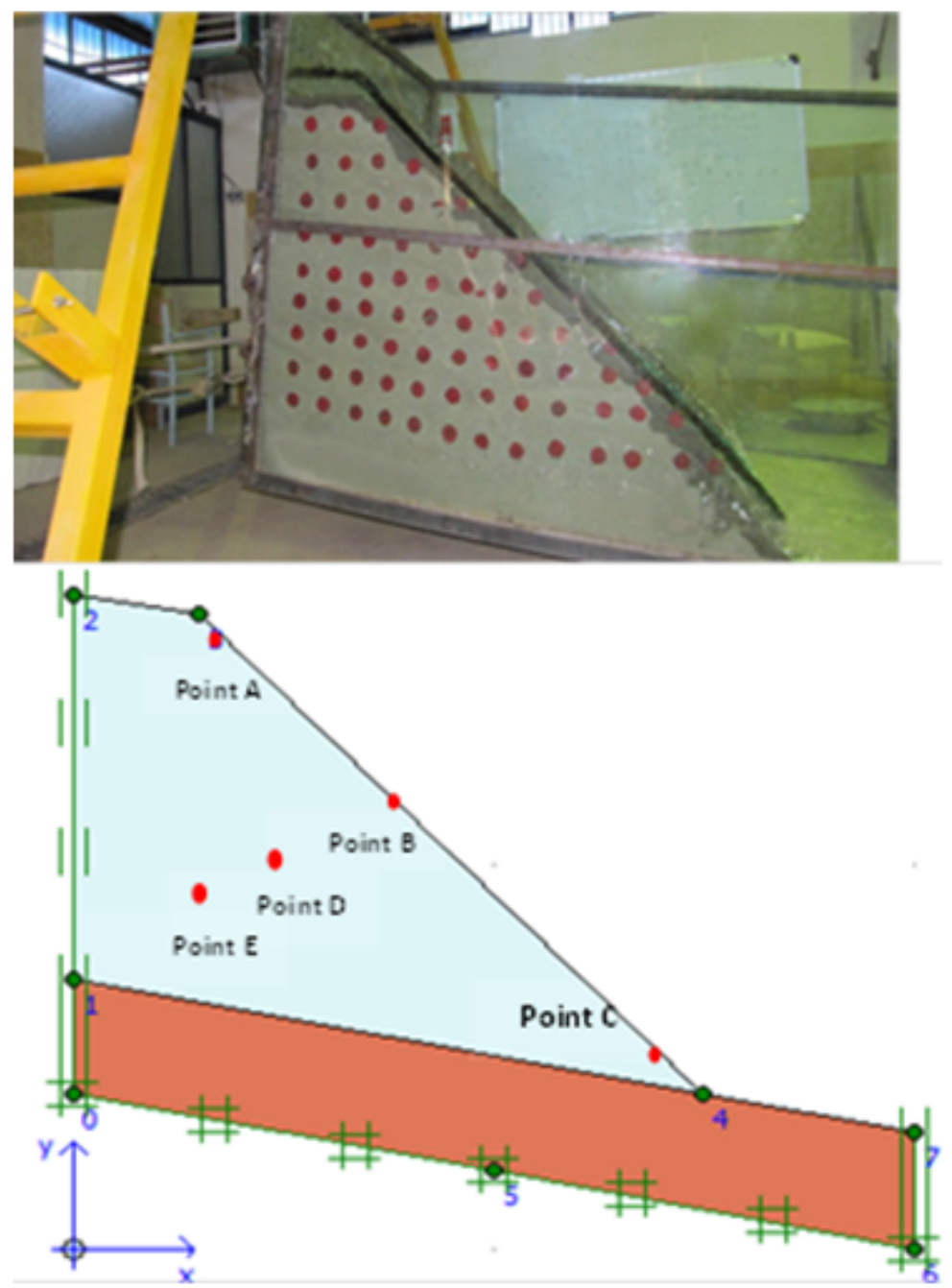
Figure 8

Set up and geometry model (a) laboratory model and (b) numerical model

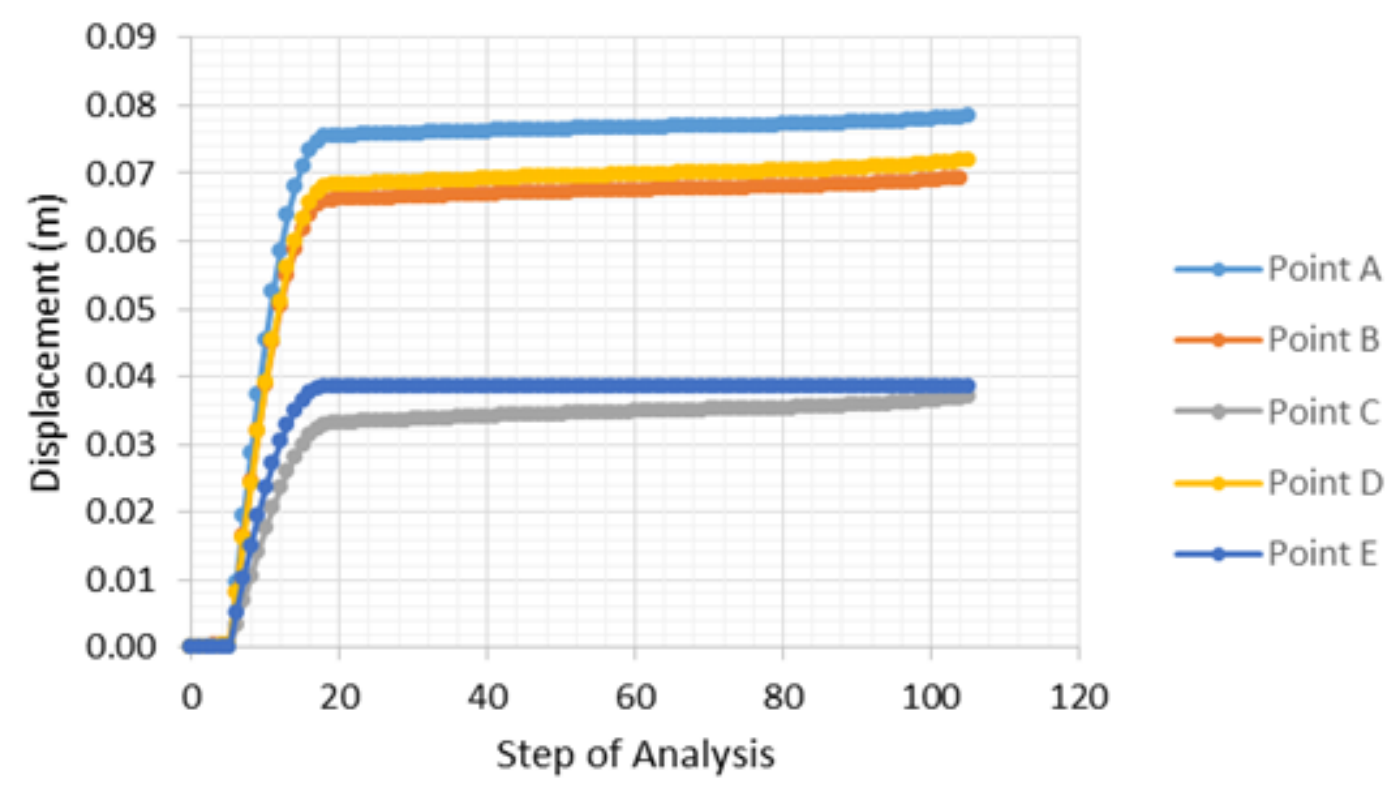

Figure 9

Displacement of the desired points in the numerical analysis

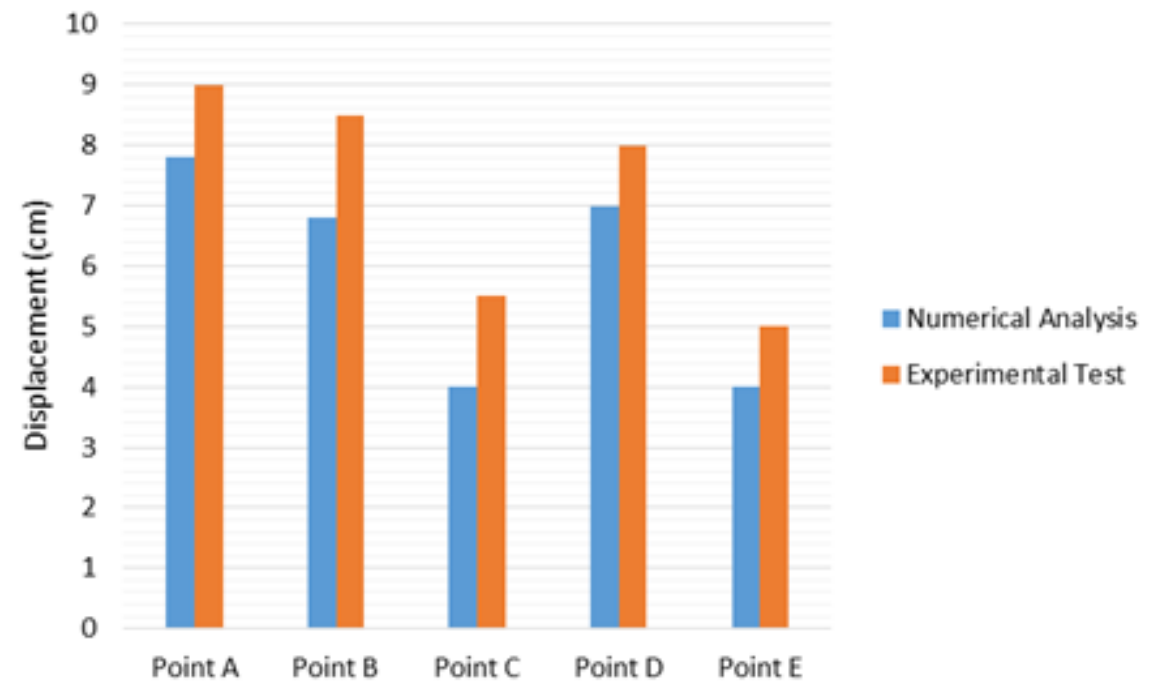

Figure 10

Comparison of displacements of points in numerical analysis and laboratory model just before the slope sliding 


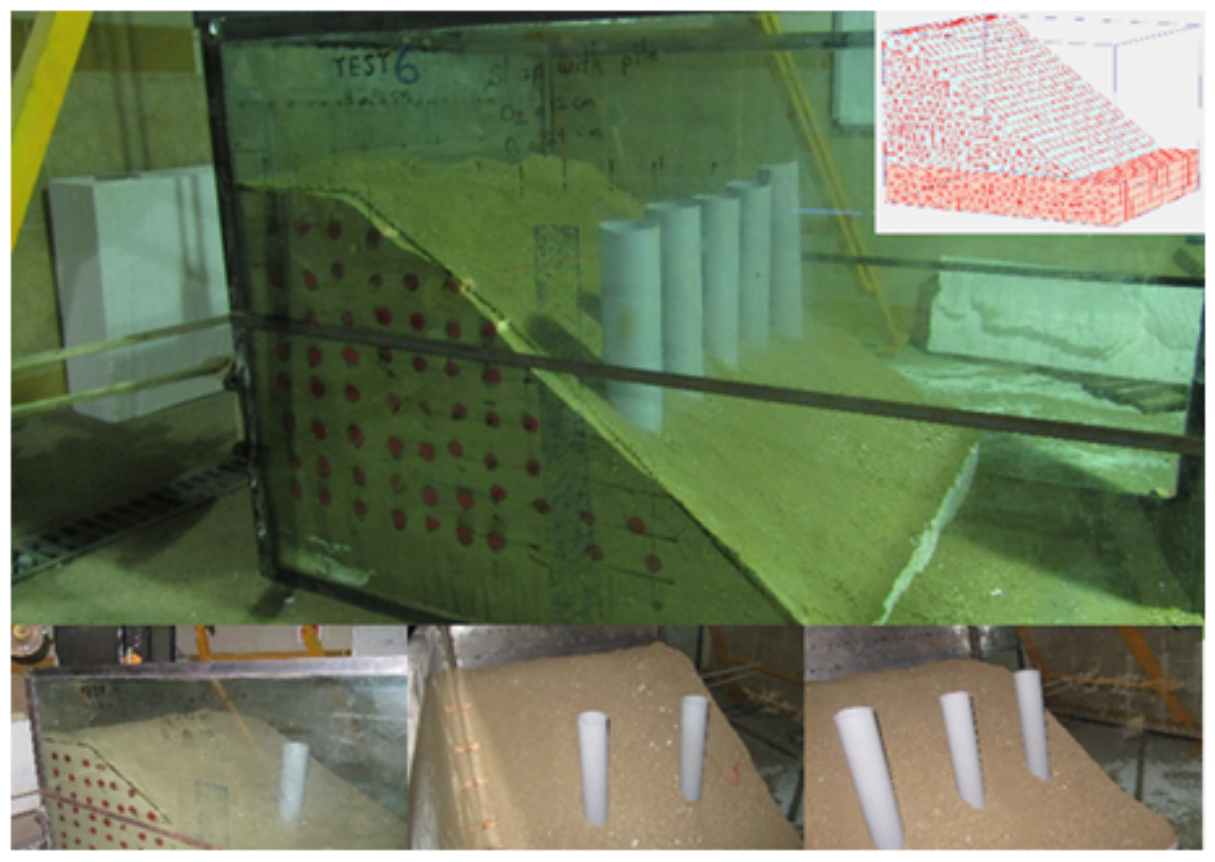

Figure 11

A Typical reinforced slope manufactured in laboratory

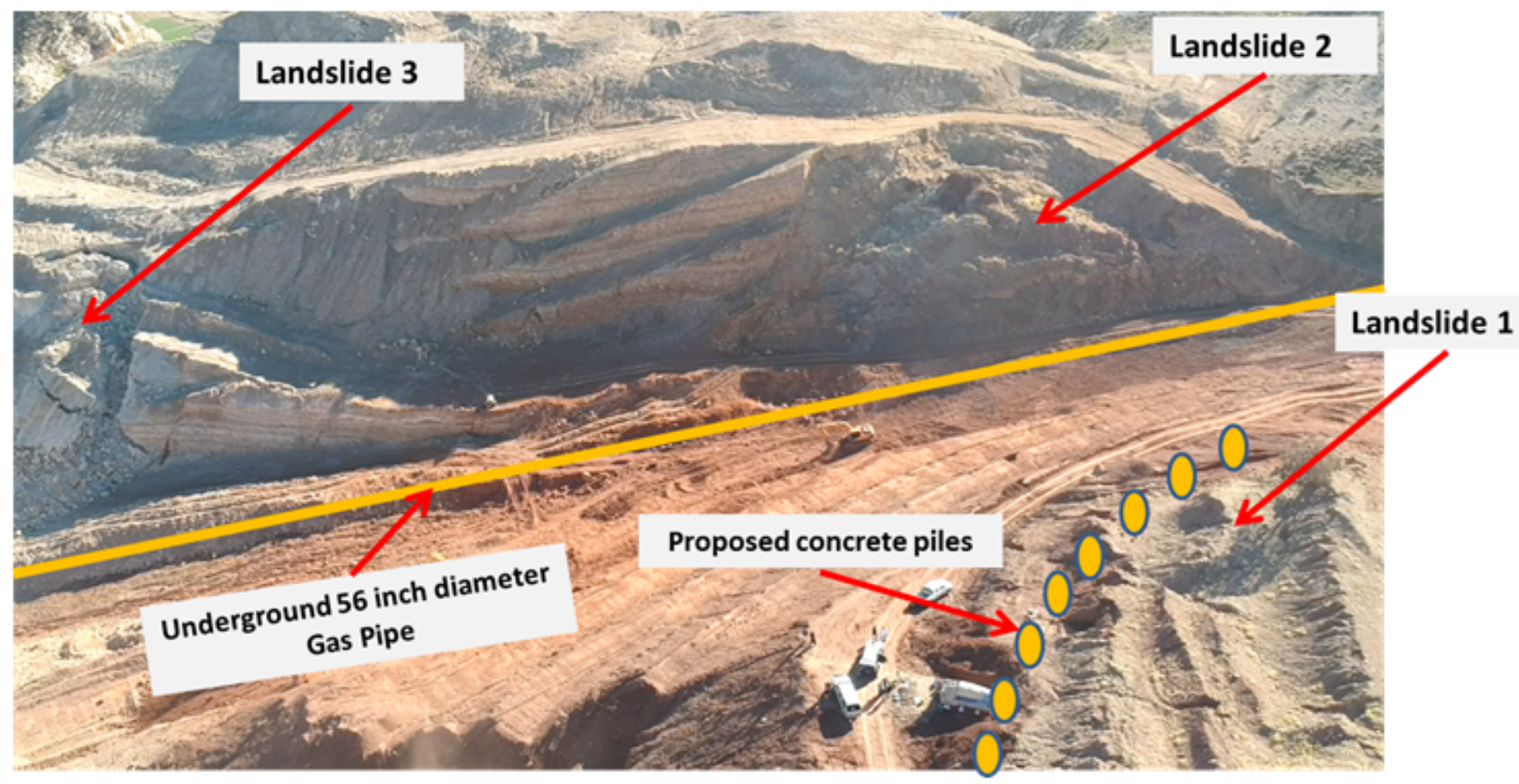

Figure 12

A Typical proposed reinforced slope by concrete pile in a The Iran Gas Trunkline (IGAT6) 